\title{
Characterizations of nickel oxide thin films prepared by reactive radio frequency magnetron sputtering
}

\author{
Z.H. Xiao*, X.F. Xia, S.J. Xu, Y.P. Luo, W. Zhong, H. Ou, E.S. Jiang \\ Xinyu Institute of New Energy, Xinyu University, Xinyu 338004, China
}

KEYWORD: Nickel Oxide; Magnetron Sputtering; Reactive Sputtering; Optical property; Electrical property

ABSTRACT: The NiO thin films were preapred by reactive radio frequency magnetron sputtering method on glass substrates. The influence of sputtering power on the crystal structure, surface morphological, optical and electrical properties was investigated using X-ray diffraction (XRD), scanning electron microscopy (SEM), ultraviolet-visible spectrophotometer (UV-VIS) and Hall effect tester, respectively. The as-preapred $\mathrm{NiO}$ thin films are polycrystalline with preferred orientation growth along (200) plane and have very high optical transmittances more than $60 \%$. All samples have a columnar structure with growth perpendicular to the film surface, and are dense, and homogeneous. With the increase of the sputtering power, a growth mode transformation appears from island growth to layer growth. The lowest resistivity of $2.4 \Omega \cdot \mathrm{cm}$ could be obtained in our samples. An optimization electrical properties of the films can be achieved by the variation of crystal quality arises from the sputtering power.

\section{Introduction}

Recently, nickel oxide (NiO) has received a lot of attention due to its excellent optical, electrical and magnetic properties as well as good chemical stability. It is a promising material for various applications such as anti-ferromagnetic layers, functional layers for solar cells, p-type transparent conductive thin films, a part of functional sensor layers in chemical sensors, material for electrochromic devices, and the p-type layer for UV detectors [1-6].

$\mathrm{NiO}$ is a typical p-type transparent oxide semi-conductor with intrinsic p-type conductivity and wide band gap energy range from 3.6 to $4.0 \mathrm{eV}$ [7]. Although stoichiometric $\mathrm{NiO}$ is an insulator, it has been reported that the resistivity of $\mathrm{NiO}$ can be lowered by increasing $\mathrm{Ni3}+$ ions, being ascribed to doping of monovalent atom such as $\mathrm{Li}, \mathrm{Na}, \mathrm{K}$ or $\mathrm{Ni}$ vacancies and interstitial oxygen in $\mathrm{NiO}$ crystallites[8-10]. The p-type conductivity of Li-doped film can be as high as $1.41 \mathrm{~S} \cdot \mathrm{cm}^{-1}$ [11]. However, the properties of $\mathrm{NiO}$ thin films for the p-type transparent conductive films is low until now. It is evident that the improvement of the material properties can be reached by the optimization of the preparation conditions.

In recent years, there are several methods could be used to prepare $\mathrm{NiO}$ thin films, which involve magnetron sputtering, plasma-enhanced chemical vapor deposition, electron beam evaporation, spray pyrolysis, sol-gel deposition, chemical bath deposition, atomic layer deposition (ALD), pulsed laser deposition, etc [12-17]. Among these methods, magnetron sputtering has been most widely useful technique having high deposition rates, uniformity over large areas of the substrates and easy control over the composition of the deposited films. The films properties depend on various deposition process parameters such as substrate temperature, sputtering power, oxygen partial pressure, sputtering pressure, substrate bias voltage and post deposition conditions. In this work, we report on the deposition of $\mathrm{NiO}$ thin films by reactive radio frequency magnetron sputtering system at room temperature and investigate the influence of sputtering power on the crystal structure, surface morphology, optical and electrical properties of $\mathrm{NiO}$ thin films.

\section{Experimental}

\section{Preparation of $\mathrm{NiO}$ thin films}

The NiO thin films were deposited on Corning 1737 glass substrates by reactive radio frequency magnetron sputtering method from a metallic nickel target (size: $60 \mathrm{~mm}$ in diameter with a thickness 
of $3 \mathrm{~mm}$ ) of $99.99 \%$ purity. The chamber base pressure was approximately $8 \times 10-4 \mathrm{~Pa}$. Pure argon was used as sputter gas and oxygen as reactive gas.

All substrates were ultrasonically cleaned with acetone, ethanol and deionised water. In addition, the target was pre-sputtered for 10 min to remove the surface oxide layers if any on the surface of the target. The distance between the target and the substrate was approximately $70 \mathrm{~mm}$. Sputtering deposition was performed under a gas pressure of $2 \mathrm{~Pa}$. The parameters during the deposition are listed in Table 1.

Table 1. Deposition conditions of the reactive radio frequency magnetron sputtered $\mathrm{NiO}$ thin films

\begin{tabular}{llllll}
\hline \multirow{2}{*}{ Sample } & \multirow{2}{*}{$\mathrm{T} /(\mathrm{oC})$} & \multirow{2}{*}{ Power/W } & \multicolumn{2}{l}{ Gas flow/sccm } & \multirow{2}{*}{ Time $/ \mathrm{h}$} \\
\cline { 4 - 5 } & & & O2 & $\mathrm{Ar}$ & \\
\hline P-50 & 25 & 50 & 10 & 20 & 2 \\
P-80 & 25 & 80 & 10 & 20 & 2 \\
P-120 & 25 & 120 & 10 & 20 & 2 \\
P-150 & 25 & 150 & 10 & 20 & 2 \\
\hline
\end{tabular}

\section{Measurements and characterizations}

The structural properties of the NiO thin films were analysed by Bruker Advance D8 X-ray diffractometer, using $\mathrm{Cu} \mathrm{K} \alpha$ radiation $(\lambda=0.1546 \mathrm{~nm})$. The surface morphology of the films was characterized by scanning electron microscopy of JEOL JSM-6700F. The thickness of the films were measured by Aquila NKD7000V thin film analysis system. For the optical properties of the films, the transmittance measurements were carried out by using Purkinje General TU-1901 ultraviolet-visible spectrophotometer with a wavelength resolution better than $\pm 0.1 \mathrm{~nm}$. The electrical properties of the $\mathrm{NiO}$ thin films were measured by Ecopia HMS-3000 Hall system. All the measurements were performed at room temperature.

\section{Results and disussion}

\section{Crystal Structure}

To investigate the crystal quality of the $\mathrm{NiO}$ thin films prepared at different sputtering power, $\mathrm{X}$-ray diffraction measurements were performed on $\mathrm{NiO}$ thin films, shown in Fig. 1. The crystal structure of the films is identified to be polycrystalline and retained the cubic structure (JCPDS data No. 780643). From the XRD patterns, it could be seen that all samples have the only one sharp peak corresponding to the diffraction of $\mathrm{NiO}$ (200) plane except the sample of P-50, indicating a strong (200) orientation and good quality of crystallinity. With the increase of sputtering power, the intensity of (200) diffraction peak become stronger, which indicates the better crystallinity.

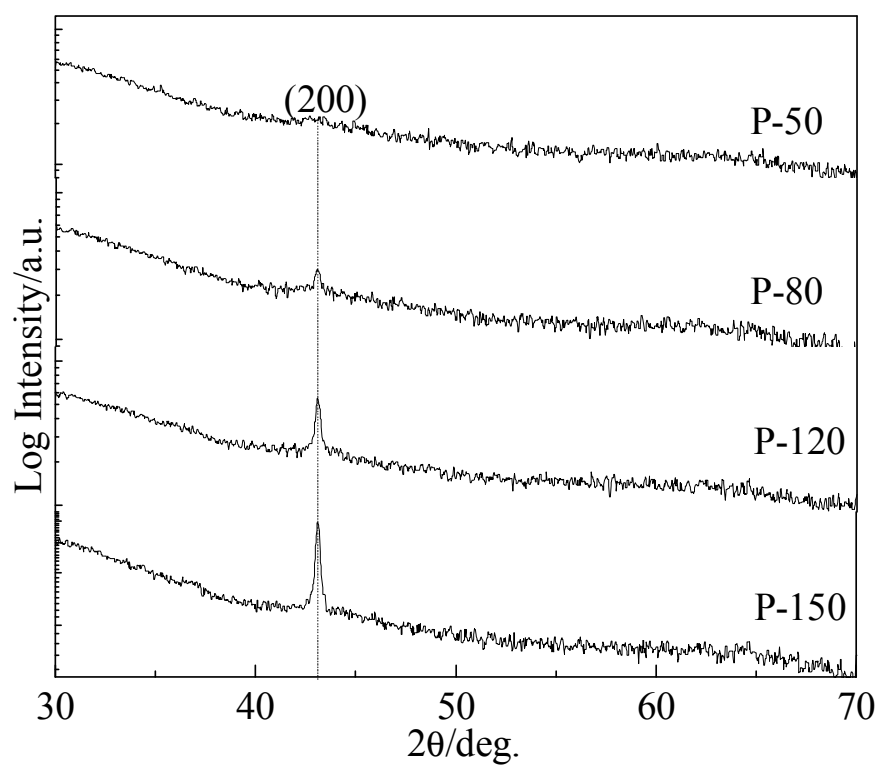

Figure 1. XRD patterns of the $\mathrm{NiO}$ thin films deposited on glass substrates at various sputtering power 


\section{Surface morphology}

The surface morphology variation of $\mathrm{NiO}$ thin films with sputtering power was observed by SEM , shown in Fig. 2. All samples had a columnar structure with growth perpendicular to the film surface, and was dense, and homogeneous. With the increase of sputtering power, the grain gradually increases from a size of 10 to $50 \mathrm{~nm}$. When sputtering power increase to $150 \mathrm{~W}$, a smoother surface was obstained. It may be attributed to the transformation of thin film growth mode [18]. When the sputtering power is low, the basic unit of film growth is less, film growth appears to island growth mode. With the increase of the sputtering power, the basic unit required for film growth also increased, and the islands on substrate gradually increases. When the sputtering power increases to a certain extent, the islands on substrate contact others, and gradually merge into a larger grain. This process results in a growth mode transformation from island growth to layer growth. The thickness of $\mathrm{NiO}$ thin film deposited at various sputtering power was given in Fig. 3. We observed that the thickness of $\mathrm{NiO}$ thin films linearly increases with the increase of sputtering power.
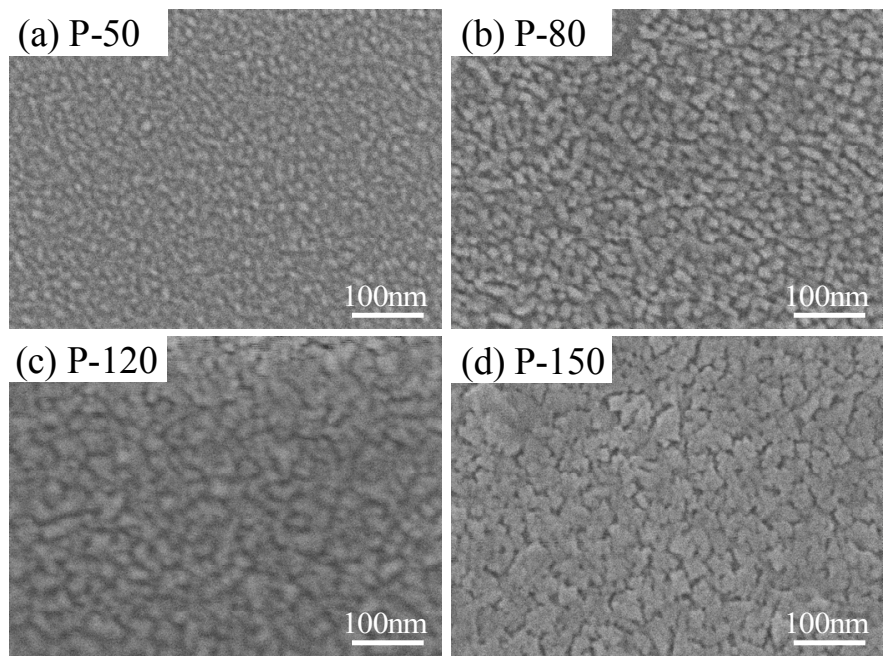

(d) P-150

Figure 2. SEM images of the $\mathrm{NiO}$ thin films deposited on glass substrates at various sputtering power

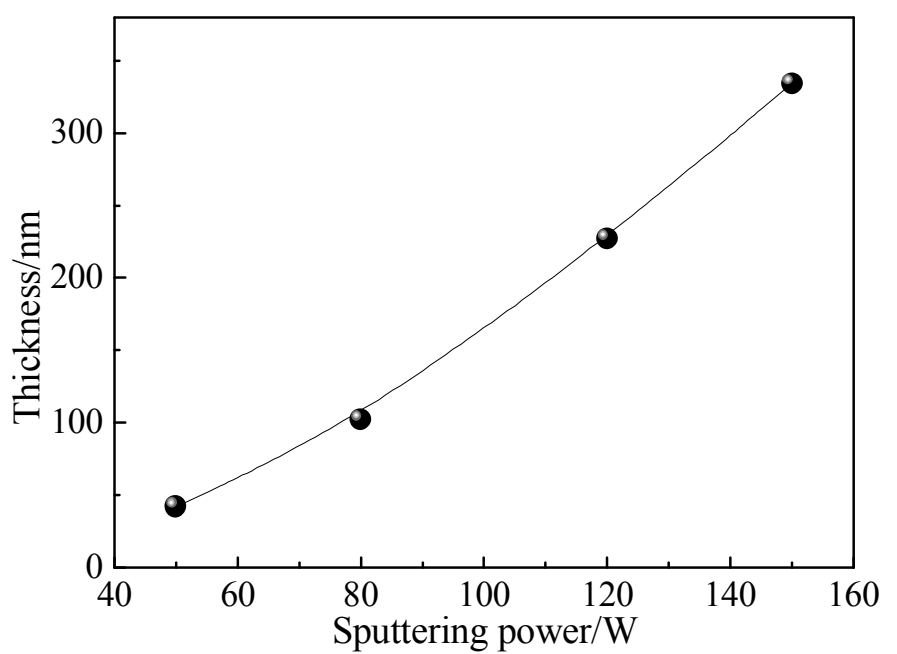

Figure 3. Thickness of the $\mathrm{NiO}$ thin films deposited on glass substrates at various sputtering power

\section{Optical and electrical properties}

The optical transmittance of all as-prepared $\mathrm{NiO}$ thin films is more than $60 \%$ at the visible range, shown in Fig.4. The transmittance of the films decreased from $90 \%$ to $65 \%$ with the increase of sputtering power from 50 to $150 \mathrm{~W}$. There are two ways for the optical loss in thin film transmission, light absorption and scattering, respectively [19]. The light absorption mainly depends on the film thickness, while the light scattering is related to the defects of the film. The thickness difference of the as-prepared samples is relatively large, The influence of light absorption caused by the thickness dominates the transmittance of the film. 


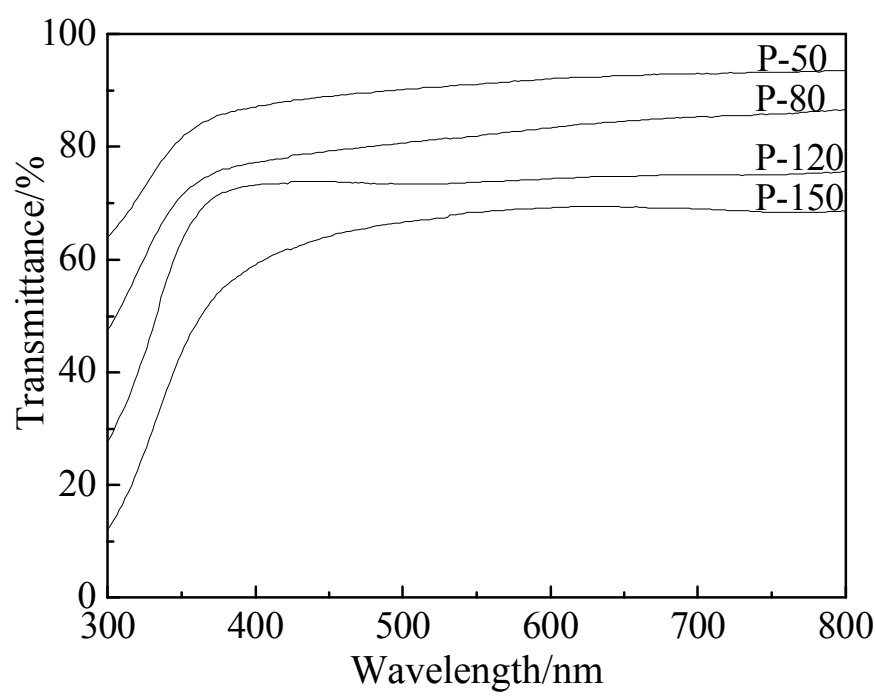

Figure 4. Transmittance of the $\mathrm{NiO}$ thin films deposited on glass substrates at various sputtering power

The resistivity of the $\mathrm{NiO}$ thin films prepared at different is shown in Fig. 5. It was clear that the electrical properties of $\mathrm{NiO}$ thin films are greatly affected by sputtering power, and the resistivity of the $\mathrm{NiO}$ thin films decreases with the increase of sputtering power. The films showed high electrical resistivity of $4.1 \Omega \cdot \mathrm{cm}$ at sputtering power of $50 \mathrm{~W}$. The electrical resistivity of the films decreased to $2.4 \Omega \cdot \mathrm{cm}$ with increasing the sputtering power to $150 \mathrm{~W}$. The electrical resistivity of $\mathrm{NiO}$ thin films has a strong dependence on the microstructural defects existing in $\mathrm{NiO}$ crystallites, such as nickel vacancies and interstitial defects [20].

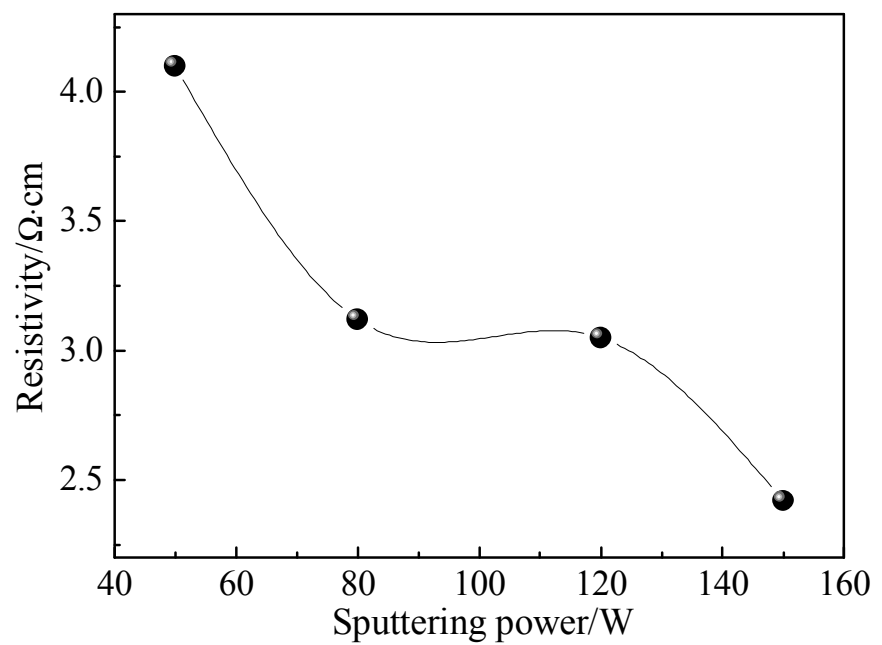

Figure 5. Resistivity of the $\mathrm{NiO}$ thin films deposited on glass substrates at various sputtering power

\section{Conclusions}

The $\mathrm{NiO}$ thin films have been preapred by reactive radio frequency magnetron sputtering method on glass substrates. The influence of sputtering power on the crystal structure, surface morphological, optical and electrical properties was investigated. The as preapred $\mathrm{NiO}$ thin films were polycrystalline with preferred orientation growth along (200) plane and very high optical transmittances more than $60 \%$. All samples had a columnar structure with growth perpendicular to the film surface, and was dense, and homogeneous. With the increase of the sputtering power, a growth mode transformation appears from island growth to layer growth. The lowest resistivity of $2.4 \Omega \cdot \mathrm{cm}$ could be obtained. 


\section{Acknowledgment}

The authors are grateful to National Natural Science Foundation of China (NO. 51462035 and NO. 51263021), and Science and Technology Landing Project in Jiangxi (NO. KJLD13099).

\section{References}

[1] W.J. Nam, Z. Gray, J. Stayancho, V. Plotnikov,D. Kwon, S. Waggoner, D.V. ShenaiKhatkhate, M. Pickering, T. Okano, A. Compaan, S.J. Fonash, ALD NiO Thin Films As a Hole Transport-Electron Blocking Layer Material for Photo-Detector and Solar Cell Devices, ECS Trans. 66(1) (2015) 275-279.

[2] Chia-Ching Wu, Cheng-Fu Yang, Effect of annealing temperature on the characteristics of the modified spray deposited Li-doped $\mathrm{NiO}$ films and their applications in transparent heterojunction diode, Solar Energy Materials and Solar Cells 132 (2015) 492-498.

[3] Z. Zhu, Y. Bai, T. Zhang, Z. Liu, X. Long, Z. Wei, Z. Wang, L. Zhang, J. Wang, F. Yan, S. Yang, High-Performance Hole-Extraction Layer of Sol-Gel-Processed NiO Nanocrystals for Inverted Planar Perovskite Solar Cells, Angew. Chem. Int. Ed. 53 (2014) 1-6.

[4] N. Park, K. Sun, Z. Sun, Y. Jing, D. Wang, High efficiency NiO/ZnO heterojunction UV photodiodeby sol-gel processing, J. Mater. Chem. C 1 (2013) 7333-7338.

[5] C. Magana, D. Acosta, A. Martinez, J. Ortega, Electrochemically induced electrochromic properties in nickel thin films deposited by DC magnetron sputtering, Solar Energy 80 (2006) 161-169.

[6] M.C. Scharber, D. Mühlbacher, M. Koppe, P. Denk, C. Waldauf, A.J. Heeger, C.J. Brabec, Design rules for donors in bulk-heterojunction solar cells--Towards $10 \%$ energy conversion efficiency, Adv. Mater. 18 (2006) 789-794.

[7] H. Sato, T. Minami, S. Takata, T. Yamada, Transparent conducting p-type NiO thin films prepared by magnetron sputtering, Thin Solid Films 236 (1-2) (1993) 27-31.

[8] S. Kerli, U. Alver, H. Yaykaşl1, Investigation of the properties of In doped NiO films, Applied Surface Science 318 (2014) 164-167.

[9] S. Kerli, U. Alver, Effect of F-doping on structural, electrical, and optical properties of NiO thin films, Crystallography Reports 59 (7) (2014) 1103-1106.

[10] Y. Reddy, B. Ajitha, P.S. Reddy, Influence of thermal annealing on structural, morphological, optical and electrical properties of NiO-Cu composite thin films, Mater. Express 4 (1) (2014) 32-40.

[11] U.S. Joshi, Y. Matsumoto, K. Itaka, M. Sumiya, H. Koinuma, Combinatorial synthesis of Lidoped $\mathrm{NiO}$ thin films and their transparent conducting properties, Appl. Surf. Sci. 252 (7) (2006) 2524-2528.

[12] R.C. Korosec, P. Bukovec, Sol-gel prepared NiO thin films for electrochromic applications, Acta. Chim. Slov. 53 (2006) 136-147.

[13] X.H. Xia, J.P. Tu, J. Zhang, X.L. Wang, W.K. Zhang, H. Huang, Electrochromic properties of porous $\mathrm{NiO}$ thin films prepared by a chemical bath deposition, Sol. Energy Mater. \& Sol. Cells 92 (2008) 628-633.

[14] T.S. Yang, W. Cho, M. Kim, K.S. An, T.M. Chung, C.G. Kim, Atomic layer deposition of nickel oxide films using Ni (dmamp) 2 and water, J. Vac. Sci. Technol. A 23(4) (2005) 12381243.

[15] M. Krunks, J. Soon, T. Unt, A. Mere, V. Mikli, Deposition of p-type NiO films by chemical spray pyrolysis, Vacuum 107 (2014) 242-246.

[16] N. Wang, C.Q. Liu, B. Wen, H.L. Wang, S.M. Liu, W.P. Chai, Enhanced optical and electrical properties of $\mathrm{NiO}$ thin films prepared by rapid radiation pyrolysis method based on the sol-gel technique, Materials Letters 122 (2014) 269-272.

[17] I. Sta, M. Jlassi, M. Hajji, H. Ezzaouia, Structural, optical and electrical properties of undoped and Li-doped NiO thin films prepared by sol-gel spin coating method, Thin Solid Films 555 (2014) 131-137.

[18] Z.H. Xiao, M. Zhang, c-axis orientation zinc oxide thin films prepared by sol-gel progress, Journal of Functional Materials 38 (12) (2007) 2015-2017. 
[19] Z.H. Xiao, M. Zhang, M.Y Guo, Investigation on zinc oxide thin films prepared by sol-gel progress, Journal of Synthetic Crystals 37 (4) (2008) 1003-1007.

[20] Y. Zhao, H. Wang, C. Wu, Z.F. Shi, F.B. Gao, W.C. Li, G.G. Wu, B.L. Zhang, G.T. Du, Structures, electrical and optical properties of nickel oxide films by radio frequency magnetron sputtering, Vacuum 103 (2014) 14--16. 